Geograficando, vol. 17, n 2, e105, noviembre 2021 - abril 2022. ISSN 2346-898X

Universidad Nacional de La Plata.

Facultad de Humanidades y Ciencias de la Educación.

Departamento de Geografía

\title{
Focos de calor registrados en el este del Chaco durante el período 2015-2020. Implicancia ambiental y manejo del fuego
}

\author{
Heat points recorded in the eastern Chaco in the 2015-2020 period. \\ Environmental implications and fire management
}

\author{
Fernando Ariel Bonfanti \\ fbonfanti1976@gmail.com \\ Departamento de Geografía. Facultad de \\ Humanidades. Universidad Nacional del Nordeste, \\ Argentina

\section{Matías Emanuel Sánchez \\ matias_141190@yahoo.com \\ Instituto de Geografía. Facultad de Humanidades. \\ Universidad Nacional del Nordeste, Argentina}

Recepción: 30 Junio 2021

Aprobación: 27 Agosto 2021

Publicación: 01 Noviembre 2021

Cita sugerida: Bonfati, F.A y Sánchez M.E. (2021). Focos de calor registrados en el este del Chaco durante el período 2015-2020. Implicancia ambiental y manejo del fuego. Geograficando, 17(2), e105.

https://doi.org/10.24215/2346898Xe105
Resumen: En las últimas décadas el calentamiento global ha intensificado incendios que destruyeron enormes áreas boscosas en diversas partes del mundo. La Argentina no ha quedado exenta de esta problemática y el Chaco mucho menos. Por tanto, el presente artículo intenta dar una mirada geográfica a la temática de los incendios forestales producidos en nueve departamentos del este de esta provincia durante el período comprendido entre los años 2015 y 2020. A través del análisis estadístico y la georreferenciación de información de diferentes fuentes, el trabajo tiene como objetivo identificar los focos de incendio que se han registrado en el área de estudio antes descrita y en ese lapso de tiempo, y caracterizar la actual gestión provincial en materia de riesgos de incendios. La producción de cartografía se realizó a partir de la utilización de Qgis. La región analizada sufrió en 2020 una gran cantidad de focos ígneos en áreas rurales que afectaron a poco más de 60000 hectáreas, destruyendo pastizales, bosques nativos e implantados $\mathrm{y}$, en consecuencia, deteriorando los suelos, la fauna silvestre, y perjudicando también la cobertura de rastrojos y a la hacienda.

Palabras clave: Focos de calor, Incendios, Chaco, Ambiente , Degradación.

Abstract: In recent decades, global warming has intensified fires that have destroyed huge forested areas in various parts of the world. Argentina has not been exempted from this problem, nor has its province of Chaco. Therefore, this article attempts to give a geographical look at the issue of forest fires that occurred in nine departments in the east of this province during the period between 2015 and 2020. Through statistical analysis and georeferencing of information from different sources, the paper aims to identify the fire outbreaks that have been recorded in the study area described above and in that period of time, and characterize the current provincial management on the subject of fire risks. The production of cartography was made from the use of Qgis. In 2020, the region under analysis suffered a large number of fire outbreaks in rural areas that affected a little more than 60,000 hectares, destroying pastures, native and planted forests and, consequently, deteriorating soils, wildlife, and also damaging stubble cover and farmlands.

Keywords: Heat sources, Fires, Chaco, Environment, Degradation. 


\section{INTRODUCCIÓN}

Los bosques en general y los incendios forestales en particular tienen una clara manifestación territorial. Estos últimos responden a una serie de factores de índole natural y fundamentalmente antrópicos. Por tanto resulta de gran interés el aporte de la geografía para conocer la distribución espacial de dicho fenómeno y determinar sus consecuencias ambientales; asimismo, conocer la forma en la que se organiza un territorio en cuanto a la gestión de este tipo de riesgos también es importante a fin de saber con qué herramientas se cuenta para hacer frente a la problemática de los fuegos.

Del bosque chaqueño puede decirse que, con su riqueza y diversidad, cumple diferentes funciones y brinda muchos servicios, por lo que es sumamente importante preservarlo para asegurar el equilibrio del ecosistema. Ha sido desde siempre el hábitat de los pueblos originarios, luego devenido en obstáculo natural durante la etapa de la conquista territorial.

A fines del siglo XIX y después de que se organizaran los Territorios Nacionales, el bosque fue valorado como un "recurso natural" que no solo aportaría ingresos económicos: su explotación constituiría además una verdadera estrategia de penetración comunicacional a través de ferrocarriles y caminos, abriendo la brecha para la instalación de pueblos, colonias agrícolas, establecimientos industriales y campos ganaderos... Sin duda, luego de esta etapa, la explotación forestal representó el primer ciclo económico del Territorio Nacional del Chaco. El avance de la frontera agrícola, primero por medio del cultivo del algodón y más tarde de otros cultivos, hizo que se le restara al bosque toda importancia ambiental y cultural, sin preocupación por conservar áreas boscosas en distintos sectores del territorio (Cuadra, 2012).

Desde hace un tiempo, el principal problema que afecta al bosque nativo en la provincia del Chaco es el desmonte o deforestación, debido al avance de la frontera agropecuaria hacia el oeste (sobre todo para cultivar soja) y al desplazamiento de la ganadería hacia el norte. Esto ha hecho que con el tiempo se hayan ido perdiendo miles de hectáreas de bosque o monte natural, generando así espacios que se han vuelto propensos a los incendios, favorecidos principalmente por las condiciones climáticas.

El fuego es un elemento esencial y natural en el funcionamiento de numerosos ecosistemas forestales, utilizado desde siempre por los pueblos originarios para la caza, la producción de calor, los enfrentamientos y la preparación de la vegetación para la agricultura. También se emplea “... como una herramienta de manejo en la producción ganadera, dado que poco tiempo después de la quema, al producirse el rebrote del estrato herbáceo, el valor nutritivo y la concentración de nitrógeno y de proteína bruta alcanzan sus niveles máximos" (Ginzburg y Adámoli, 2005, p. 106). Desempeña una función importante en el mantenimiento de la salud de ciertos ecosistemas, pero a causa del uso (y abuso) humano del fuego, los incendios son ahora una amenaza para muchos bosques y su biodiversidad (Dennis et al., 2001). A su vez, produce alteraciones en el ecosistema: cambios en la vegetación, el suelo o el paisaje; modificaciones en el balance de energía y agua; pérdidas económicas o daños en la salud y en la vida de las personas (Di Bella et al., 2008).

El objetivo de este trabajo es identificar los principales focos de calor que se han registrado durante el período 2015-2020 en el este chaqueño, comprendido por los departamentos Libertador General San Martín, Sargento Cabral, Presidencia de la Plaza, General Dónovan, Libertad, Tapenagá, San Fernando, $1^{\circ}$ de Mayo y Bermejo, para poder advertir algunas de sus causas y consecuencias, sobre todo las ambientales. Por otra parte, también se describen brevemente las características de la actual gestión provincial en materia de riesgos de incendios. 
Cabe señalar que se seleccionó el sector oriental de la provincia, correspondiente a la ecorregión Chaco Húmedo (de características más bien ganaderas), para tener una referencia distinta a la del sector occidental (Chaco Seco), que es hacia donde se expande la frontera agrícola y presenta, según Navarro (2016), la mayor cantidad de ocurrencia de focos de calor sobre coberturas de bosque. En cuanto al período 2015-2020, se consideró oportuno tomar esos seis años para poder apreciar la tendencia de ocurrencia de estos fenómenos y de esta manera evidenciar la excepcionalidad del año 2020, que además de la pandemia por el COVID-19, presentó condiciones hidrometeorológicas anómalas para la región en estudio.

\section{MARCO CONCEPTUAL}

El marco normativo que existe en la República Argentina referido a incendios forestales y rurales data del año 2013, cuando se promulgó la Ley Nacional de Manejo de Fuego N. ${ }^{\circ} 26.815$, que contempla que se abocará a

(...) las acciones y operaciones de prevención, presupresión y combate de incendios forestales y rurales que quemen vegetación viva o muerta, en bosques nativos e implantados, áreas naturales protegidas, zonas agrícolas, praderas, pastizales, matorrales y humedales y en áreas donde las estructuras edilicias se entremezclan con la vegetación fuera del ambiente estrictamente urbano o estructural. Asimismo alcanza a fuegos planificados, que se dejan arder bajo condiciones ambientales previamente establecidas, y para el logro de objetivos de manejo de una unidad territorial (Ley Nacional N. ${ }^{\circ} 26.815$, art. 2).

Además, según lo estipulado en su artículo 3, se creó el Sistema Federal de Manejo del Fuego en el ámbito del Ministerio de Ambiente y Desarrollo Sostenible, algunas de cuyas atribuciones son: a) confeccionar un Plan Nacional de Manejo del Fuego; b) desarrollar e implementar un Sistema Nacional de Alerta Temprana y Evaluación de Peligro de Incendios; c) desarrollar un Programa de Fortalecimiento Operativo, promoviendo un nivel de organización, e incorporación de equipamiento y de tecnologías que garanticen la actuación segura y eficiente de los recursos terrestres y aéreos de apoyo al combate del fuego, etc.

Finalmente cabe consignar que esta norma fue modificada parcialmente en diciembre de 2020 con la sanción de la Ley N. $^{\circ} 27.604$, que realiza cambios en el artículo 22 bis de la ley anterior y prohíbe cambiar el uso de zonas incendiadas por el término de 60 años, sobre todo cuando se dañan superficies de bosques nativos, áreas naturales protegidas o humedales.

En la actualidad, la mayoría de los incendios están ligados a la actividad ganadera o agrícola (Kunst, Bravo y Panigatti, 2003). Se puede definir un incendio forestal como un fuego que se propaga libremente con efecto no deseado para la vegetación y sin estar sujeto a control humano. Cuando involucra zonas no boscosas y/o no aptas para la forestación, se utiliza el término incendio rural, que alude al que se desarrolla en áreas rurales, afectando vegetación de tipo matorral, arbustal y/o pastizales. A veces causa un gran daño ecológico en vastas extensiones de terreno, sobre la flora, la fauna, los recursos hídricos y los suelos. Provoca daños económicos sobre productos madereros y no madereros como alambrados, galpones, corrales, viviendas, etc., y al mismo tiempo afecta el paisaje (Ministerio de Ambiente y Desarrollo Sostenible, 2021).

Los incendios inician un proceso de sucesión, por lo tanto son eventos que están inherentemente unidos a la sucesión vegetal. Sin embargo, los ecosistemas poseen mecanismos de resistencia y resiliencia que les confieren la habilidad de resistir el daño generado por las llamas y recuperarse del mismo (Landi, 2018, p. 3).

En el Chaco Húmedo, el fuego es un componente ecológico muy importante en el diseño de la vegetación, al ser un elemento regulador de la dinámica de sus ecosistemas de sabanas y pastizales. Naturales o provocados, los incendios son una parte fundamental del diseño y el funcionamiento del paisaje chaqueño (Ginzburg y Adámoli, 2005), sobre todo en el este, donde la productividad del estrato herbáceo es muy elevada, lo que genera una importante acumulación de material combustible (Kunst, Bravo y Panigatti, 2003).

En este sentido, resulta de vital importancia contar con material cartográfico en el que se puedan identificar los sitios que probablemente sean afectados por el fuego o en los que se han producido focos ígneos. Para tal fin se utilizan los denominados mapas de focos de calor. 
Foco de calor (hot spot) es la expresión que se utiliza para referirse a un incendio potencial, es decir, la presencia de un incendio asegura que en el mapa de focos aparecerá un punto indicador siempre y cuando no haya nubes sobre la región (Comisión Nacional de Actividades Espaciales - Conae, 2014).

Según Di Bella et al. (2008), la detección de focos de calor se basa en la capacidad de algunos sensores remotos de capturar la energía emitida por las superficies en las longitudes de onda correspondientes al infrarrojo medio y térmico del espectro electromagnético. De acuerdo a las temperaturas que alcanzan los incendios (entre $300{ }^{\circ} \mathrm{C}$ y $1500{ }^{\circ} \mathrm{C}$ ), se establecen umbrales asociados a la energía emitida en determinada longitud de onda, los cuales permiten identificar los focos de calor (Navarro, 2016).

Ahora bien, según lo establecido en el Instructivo de Visualización de Focos de Calor de la Conae (2014), que en el mapa de focos aparezca un punto indicador no significa que en ese lugar haya un incendio. En este último caso, las altas temperaturas del terreno detectadas (anómalas respecto de las temperaturas de la superficie del entorno de dicho punto) solo están indicando que puede haber —o habrá, en el corto plazo de horas- un incendio.

La confiabilidad estadística es un elemento clave a considerar en la lectura de este tipo de mapas, ya que agrega veracidad a los datos que se representan en el material cartográfico. La precisión es el resultado de pruebas repetitivas de las observaciones, que minimizan los errores de lectura. Debe tenerse en cuenta que esas lecturas se realizan a través de imágenes satelitales aplicando cálculos matemáticos complejos.

\section{SITUACIÓN REGIONAL Y MUNDIAL DE LOS INCENDIOS}

En los últimos tiempos, una de las noticias que más acaparó la atención de los medios internacionales fue la de los grandes incendios forestales registrados en California, EE. UU., durante varios meses del año 2018, al punto de considerarlos entre los más destructivos de la historia de ese estado.

En el año 2019, la crisis de los incendios forestales puso a los bosques sudamericanos en el centro de la mirada regional y mundial. Solo entre los meses de agosto y septiembre de ese año se registraron en Brasil un total de 105109 puntos calientes (para su detección se utilizaron imágenes del satélite GOES-12, aplicando el algoritmo multiespectral "Queimada”). Según el Instituto Nacional de Pesquisas Espaciais, INPE, la mayoría de aquellos estaban en la región amazónica. Amplias zonas boscosas de Bolivia y del Gran Chaco americano también fueron afectadas por fuegos descontrolados que amenazaron la supervivencia de la biodiversidad y de las comunidades que allí habitan.

Aunque la mayoría de los incendios son causados por la acción humana, el problema — de larga dataes consecuencia de múltiples factores que interactúan de manera simultánea. Estos son principalmente la deforestación, el uso del fuego para limpiar el terreno y la falta de controles y de aplicación de normativas sobre el medio ambiente, en el marco de un modelo productivo basado en la apropiación de la tierra. Además, condiciones ambientales como la sequía y el calentamiento global favorecen la expansión del fuego. Pero todos estos factores actúan bajo un paradigma que genera las condiciones para su existencia: el paradigma del éxito basado en la acumulación y el poder (Nemirovsky, 2019).

En Australia se desataron hacia fines de 2019 feroces incendios cuyas conmovedoras imágenes en los medios de comunicación mostraban a bomberos y ciudadanos anónimos rescatando a koalas heridos en su intento por escapar de las llamas. El país estuvo envuelto por una espesa capa de humo contaminante hasta que las lluvias torrenciales — que anunciaban la llegada del verano austral — empezaron a asistir en las arduas tareas de extinción de aquellos incendios forestales (Puig Soler, 2020). Las cifras, sin precedentes, han dejado un registro de cerca de cinco millones de hectáreas calcinadas, la mayoría durante los meses de primavera en el hemisferio sur (septiembre a diciembre), producto de una serie de anomalías meteorológicas muy vinculadas al cambio climático antropogénico (Vegas, 2020).

El 2020 ha sido todavía peor ya que el número de incendios forestales creció: solo en abril, al menos un 17 $\%$ a nivel global comparado con el año anterior (Argentina Forestal, 2020). Sin duda, un año como ningún 
otro, en el que el mundo entero se vio sorprendido por la pandemia de COVID-19, que dejó -y lo sigue haciendo aún-, implicancias sociales y económicas que van a cambiar el mundo para siempre. Mientras la comunidad internacional enfoca su atención en combatirla, la Argentina también se ha visto afectada por una gran cantidad de incendios forestales.

\section{MATERiales Y MÉTODOS}

La metodología empleada es de carácter cuantitativo. Las principales fuentes de datos fueron el Instituto Nacional de Pesquisas Espaciales de Brasil y el Sistema Nacional de Manejo de Fuego de la República Argentina, que nos permitieron elaborar los gráficos que muestran la situación actual y la evolución de los incendios forestales en Argentina.

Para confeccionar la cartografía correspondiente a los focos de calor que se registraron entre 2015 y 2020 en el este de la provincia del Chaco se utilizó información procedente del Centro de Documentación e Información de la provincia del Chaco (Cedei), que a su vez obtiene los datos de la Conae. Esta última agencia los recoge a través de los sensores "Modis" (Espectrorradiómetro de Imágenes de Media Resolución, de los satélites Aqua y Terra) y "Viirs" (Conjunto de Radiómetros de Imágenes Infrarrojas Visibles, de los satélites NOAA-20 y Suomi NPP).

Los datos aportados por el Cedei tienen una escala provincial, por lo que se realizó un recorte a escala departamental utilizando el SIG libre Qgis; al mismo tiempo se efectuó un corte temporal para los años 2015, 2016, 2017, 2018, 2019 y 2020. Este producto permite acceder a una estimación del nivel de confianza de los datos que oscila entre el 0 y el $100 \%$ y se les asigna una de las tres clases de fuego: baja confianza, nominal y de alta confidencialidad (Sistema de Información de Biodiversidad, 2016). En el caso seleccionado para este trabajo, se utilizaron los focos de calor con una confianza igual o superior a $70 \%$ y se realizó un conteo de los focos por departamento por cada período de tiempo.

Para calcular las hectáreas quemadas se tomó en cuenta dicha cantidad de focos de calor y luego se aplicó la siguiente fórmula:

\section{Foco $=1$ Pixel sensor VIIRS $=14,06$ ha}

De esta manera se procedió al cálculo de cada período y por departamento del área de estudio.

Para la representación de las zonas de sequía, se georreferenció la información tomada del servidor SISSA (Sistema de Información para Sequías para el Sur de Sudamérica), donde las categorías de sequía se calculan basándose en percentiles de precipitación acumulada tomando como período de referencia los 35 años comprendidos entre 1982 y 2016 inclusive. Sobre la base de estos percentiles se asigna una categoría de sequía según las especificaciones del United States Drought Monitor.

Las diferentes categorías de sequía se presentan sombreadas con distintos colores. Las zonas amarillas indican condiciones "anormalmente secas", pero a las que no se considera propiamente sequía, sino que refieren a áreas que pueden estar entrando o recuperándose de condiciones secas. Las categorías restantes remiten a cuatro grados de sequía de severidad creciente. Los tonos anaranjados claros indican "sequía moderada"; el anaranjado, "sequía severa"; el rojo, "sequía extrema", y el bordó, "sequía excepcional". Las áreas blancas, categorizadas como "no seco", muestran que se están experimentando condiciones normales a húmedas. 


\section{Resultados}

\section{Situación de los incendios forestales en la República Argentina}

Antes de mostrar la situación en el área de estudio, exponemos brevemente el panorama nacional. En primer lugar, el gráfico N. 1 muestra la evolución de los incendios forestales que se han producido en Argentina desde el año 2001 hasta el 2020.

\section{GRÁFICO N. ${ }^{\circ} 1$}

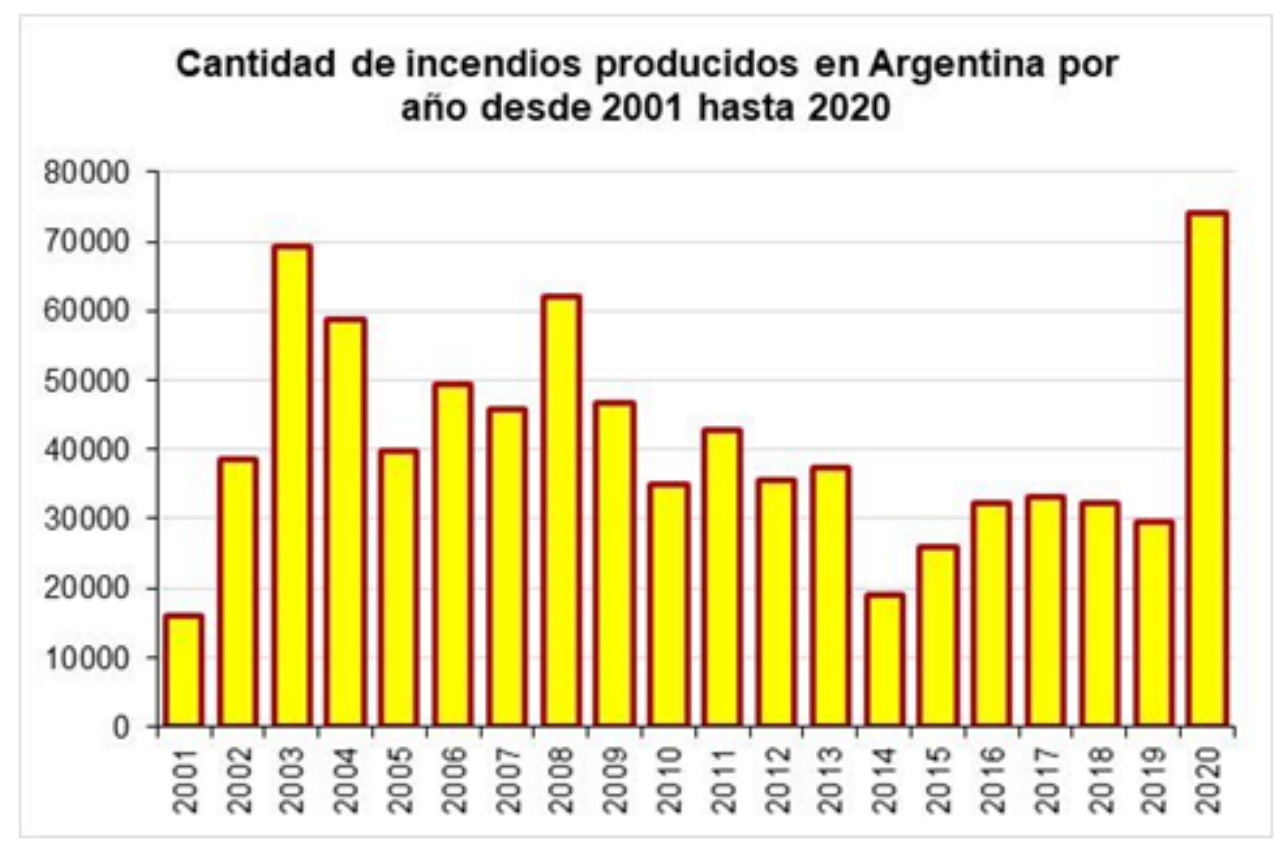

Fuente: Elaboración propia sobre la base de estadísticas del INPE

Como se aprecia en el gráfico, en el año 2020 se registró en Argentina una cifra récord de incendios (no de superficie quemada), con un total de 74.113 focos ígneos, el pico máximo anual registrado de manera satelital en los últimos veinte años. La anterior cifra histórica se había producido en el año 2003, durante el cual se registraron 69.317 puntos calientes.

Los datos se desprenden de un análisis del Instituto Nacional de Investigaciones Espaciales de Brasil (INPE por sus siglas en portugués), que hace una medición satelital desde 1999 en la que evalúa, mes a mes, el número de puntos calientes de los países de América del Sur. El organismo, que posee una amplia legitimidad internacional, se hizo conocido en 2019, cuando denunció la desidia del gobierno del presidente Jair Bolsonaro para frenar los incendios en la Amazonia. Solo en cuatro oportunidades —-2003, 2004, 2008 y 2020 - la cantidad de incendios pasó los 50.000, según datos del INPE, y 2020 fue el año en que se registró el valor más alto.

Para poder medir los focos de calor en nuestro país se utiliza el Sistema de Información sobre Incendios para la Gestión de Recursos (Firms) de la NASA. Además, Argentina usa dos mecanismos de sensores: el Modis, que sirve para ver los datos históricos, y el Viirs, más preciso, que comenzó a utilizarse a partir de 2012.

Durante todo el 2020, casi la totalidad de las provincias argentinas (excepto San Juan) tuvieron focos de incendios activos, según datos del Sistema Nacional del Manejo del Fuego (SNMF). La más afectada fue Córdoba, donde se quemaron un total de 331.676 hectáreas, superficie que equivale a más de diez veces la de la Ciudad de Buenos Aires (de ese total, 182.724 ha fueron de bosques); le siguieron Entre Ríos (309.760 ha), Chaco (85.000 ha) y Salta (71.869 ha), según puede apreciarse en el gráfico N. ${ }^{\circ} 2$. 
GRÁFICO N.²

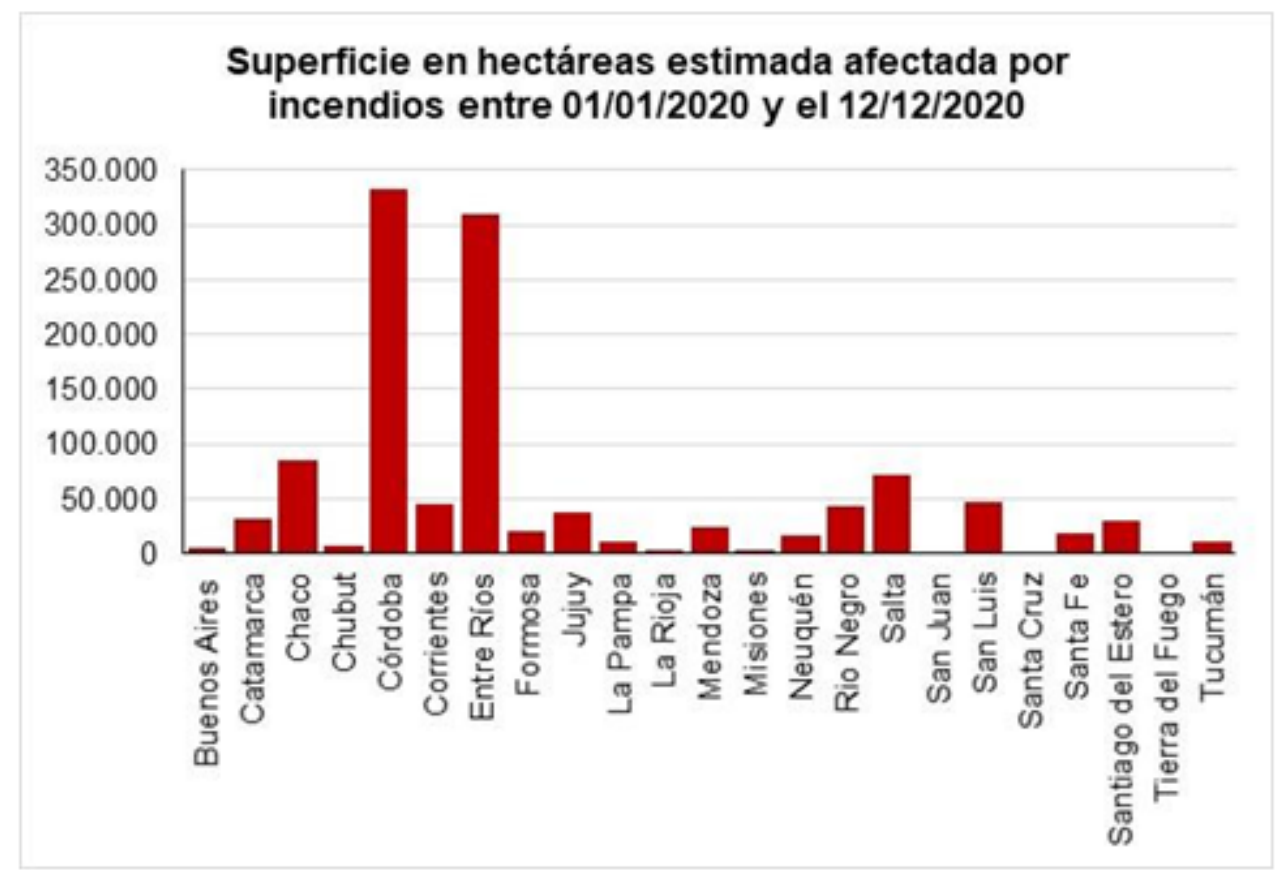

Fuente: Elaboración propia sobre estadísticas del Servicio Nacional de Manejo de Fuego. En https://www.argentina.gob.ar/sites/default/files/1-nov-reporte_incendios.pdf

Si bien la cantidad de focos de calor en el último año ha sido alta, no siempre hay una correlación directa entre estos y la superficie realmente afectada por esos fuegos. Lo que sí es cierto es que en los últimos años los perjuicios fueron muy superiores respecto a la superficie damnificada, sobre todo en la región Centro, Noreste y Noroeste, lo cual ha hecho que se comience a hablar de ecocidio intencional.

$\mathrm{Al}$ respecto, muchas asambleas ambientales y organizaciones que luchan contra el fuego hablan de la situación en Argentina como de un ecocidio masivo y deliberado y les apuntan a los intereses económicos que pretenden reemplazar áreas de bosque nativo por explotaciones agropecuarias, negocios inmobiliarios y desarrollos urbanísticos (Magnani, 2020).

En ese sentido, si señalamos únicamente a los negocios inmobiliarios o la extensión de las fronteras agropecuarias como los grandes culpables, estaríamos desconociendo el verdadero problema y desviando la responsabilidad de la gestión del riesgo. Lo que falta es una verdadera estrategia de alcance nacional que maneje con responsabilidad esta situación, por ejemplo a través de la regulación y control de la quema de pastizales, una práctica muy utilizada en la agricultura.

En relación con lo anterior, una de las formas de prevenir los incendios forestales es mediante la realización de quemas controladas para evitar la acumulación de materia seca, combustible que ante un foco ígneo puede transformarse en un incendio. La mayoría de las provincias cuenta con normas específicas que habilitan la realización de estas quemas, que deben efectuarse bajo condiciones ambientales precisas: las temperaturas deben ser inferiores a los $20^{\circ}$, el viento debe oscilar entre cinco y 15 kilómetros por hora y se tienen que haber registrado lluvias en los últimos días para que haya un rango de humedad del 40 al $50 \%$. Por lo tanto, se necesita un enfoque basado en la ciencia para pronosticar el riesgo y priorizar intervenciones, elementos críticos para evitar que las quemas se transformen en incendios. Es necesario que se planifique en todas las regiones susceptibles una red de cortafuegos que permita manejar los incendios. La insuficiente traza y mantenimiento de cortafuegos hace posible que los incendios avancen sin control (Argentina Forestal, 2020). 


\section{CaUsas de los inCENDIOS}

Si bien es cierto que existen factores climáticos que influyen en la propagación del fuego - la falta de precipitaciones, las temperaturas elevadas, el bajo porcentaje de humedad, las heladas constantes y los vientos fuertes-, según el Servicio Nacional de Manejo de Fuego el $95 \%$ de los incendios forestales en la Argentina son producidos por causas antrópicas, es decir, por fuegos intencionales para deforestar o por un fogón mal apagado.

El factor antrópico que mayor incidencia tiene es el uso del fuego como herramienta de desmonte, no solo para limpieza de pastizales y búsqueda de rebrotes, sino como instrumento de reemplazo de la topadora para avanzar con la frontera agropecuaria. Por otra parte, entre las causas meteorológicas destacamos principalmente a la sequía, que se presume es una de las consecuencias del cambio climático.

\section{DESCRIPCIÓN DEL ÁREA DE ESTUDIO}

Nuestra área de estudio comprende nueve departamentos del este de la provincia del Chaco: Libertador General San Martín, Sargento Cabral, Presidencia de la Plaza, General Dónovan, Libertad, $1^{\circ}$ de Mayo, Bermejo, San Fernando y Tapenagá, como puede observarse en el mapa N. ${ }^{\circ}$ 1. Entre todos ocupan una superficie total de $26.332 \mathrm{~km}^{2}$, que representa el $26,4 \%$ del territorio chaqueño.

La provincia presenta un clima subtropical sin estación seca en el extremo oriental y con estación seca en el resto del territorio, con precipitaciones que se concentran en el otoño y en verano. Los inviernos son fríos y por lo general muy secos, lo cual genera un ambiente proclive a la ocurrencia de incendios:

(...) la temporada de fuego en la región chaqueña está asociada directamente con el patrón climático: comienza en juniojulio, luego que las primeras heladas 'fuertes' acondicionan el combustible - particularmente el herbáceo- y finaliza con las primeras lluvias importantes que ocurren durante octubre-noviembre y que generan el aumento la humedad relativa del aire y la producción de nuevo tejido vegetal (Kunst, 2011, p. 85).

Ahora bien, si tenemos en cuenta las fisonomías o paisajes vegetales dominantes, que se perciben a simple vista y que resultan de la influencia combinada de los factores climáticos, topográficos y edáficos, esta región se corresponde en gran parte con la que Morello y Adámoli (1968) denominan Chaco de esteros, cañadas y selvas de ribera y Paraguay-Paraná. En su trabajo sobre grandes unidades de vegetación y ambiente, estos autores las identifican como subregiones del este chaqueño, al igual que la denominada Dorsal Agrícola Paranaense (Alberto, 2006). En esta subregión, los esteros, pajonales y pastizales se alternan con los bosques en proporciones muy variables. Hacia el oeste de la misma dominan los bosques y hacia el este, los paisajes abiertos. En general persisten tres grandes tipos de bosques - bosque muy alto de las riberas de los ríos, llamados "selvas de ribera"; bosque alto, formado por una trama de leñosas de madera dura como el quebracho y el urunday; y bosque bajo, donde dominan los algarrobos-, y dos ambientes de graminiformes - el pastizal no inundable alto en parte agrícola y el pajonal con espejos de agua, una parte del año formando cañadas o bañados- (Morello y Adámoli, 1968). 


\section{MAPA N. ${ }^{\circ} 1$}

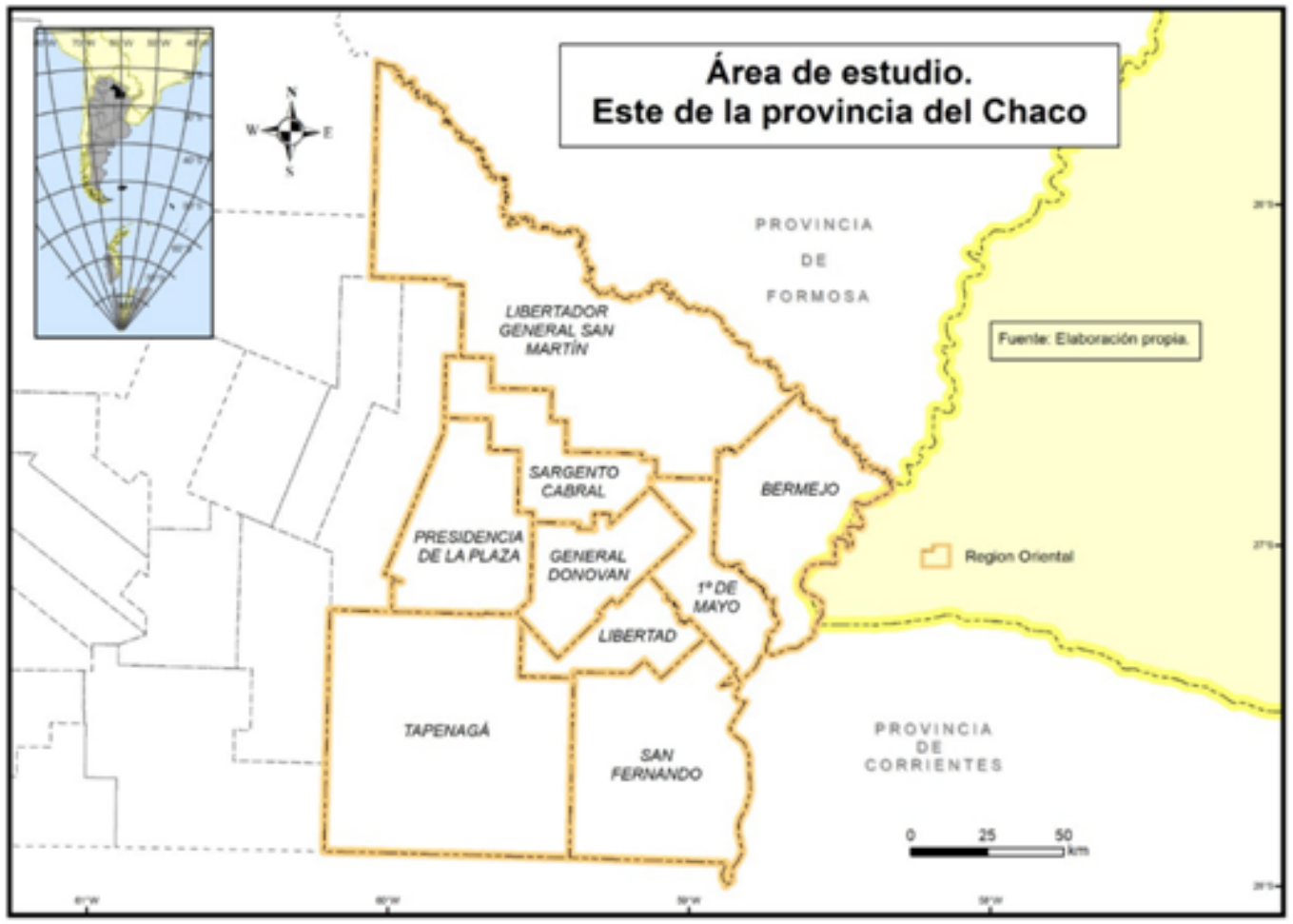

Fuente: Elaboración propia

Focos de CALOR EN EL ESTE Del Chaco ENTRE 2015 y 2020

Según información del Cedei, los focos de incendio con una confianza del $70 \%$ o más han mantenido un comportamiento bastante regular entre 2015 y 2019, con valores que oscilaron entre 538 focos ígneos en 2015 y 1417 en 2017. Sin embargo, como puede apreciarse en el gráfico N. ${ }^{\circ} 3$, el año 2020 ha mantenido una correlación directa con el panorama nacional antes descrito y arrojó un valor récord de 4.500 focos de calor, que a su vez representaron un total de 63.000 hectáreas afectadas. 
GRÁFICO N. 3

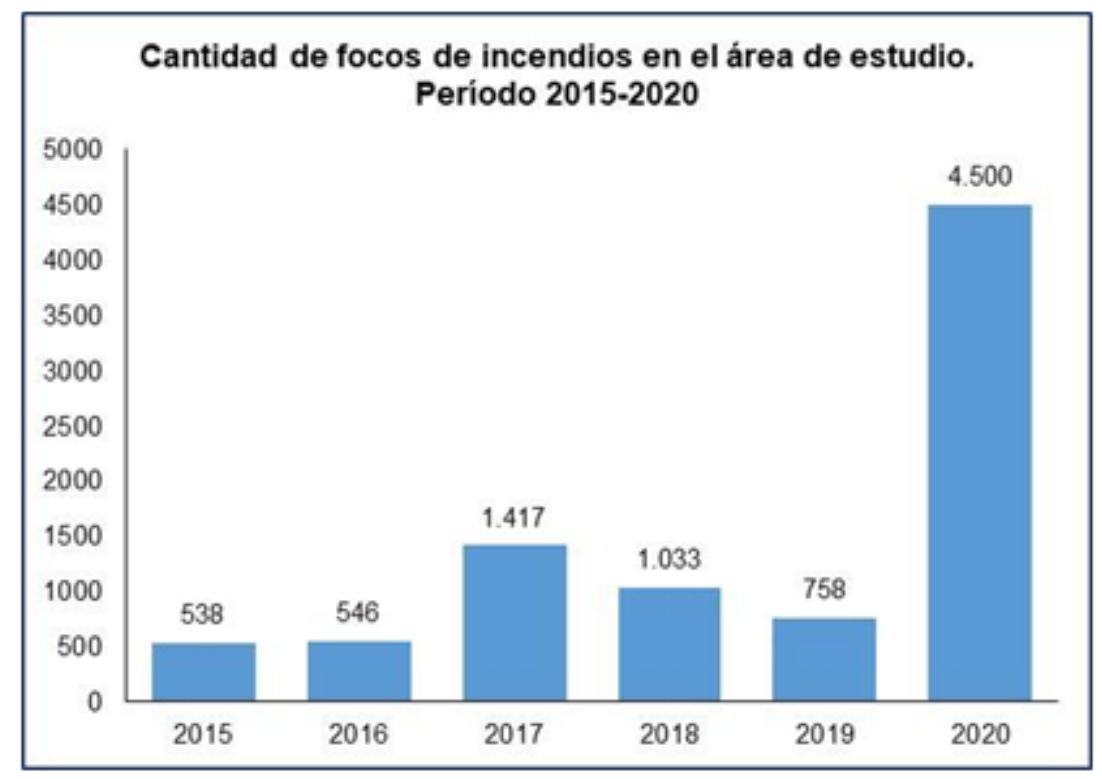

Fuente: Elaboración propia sobre la base de estadísticas del Cedei (2021)

A efectos de comparar los dos extremos en esta escala temporal se representó cartográficamente la distribución de los focos de calor en el área de estudio en dos mapas diferentes, uno para 2015 y otro para 2020.

En primer lugar se realizó el mapa de focos de calor correspondiente al año 2015 (mapa N. ${ }^{\circ}$ 2). Para elaborar el mismo se procedió a seleccionar los nueve departamentos del este provincial de la capa "Departamentos" y las capas "Provincias" y "Límite Internacional" provenientes del servidor de capas GIS del Instituto Geográfico Nacional. Luego se añadieron los focos de calor provistos por el Cedei, con una selección previa de aquellos puntos que han sido iguales o superiores al $70 \%$ de confianza. En este mapa se aprecia una distribución bastante homogénea de los 538 focos ígneos que se registraron durante ese año en el área de estudio, aunque con una mayor concentración en el departamento San Fernando. 
MAPA N. ${ }^{\circ} 2$

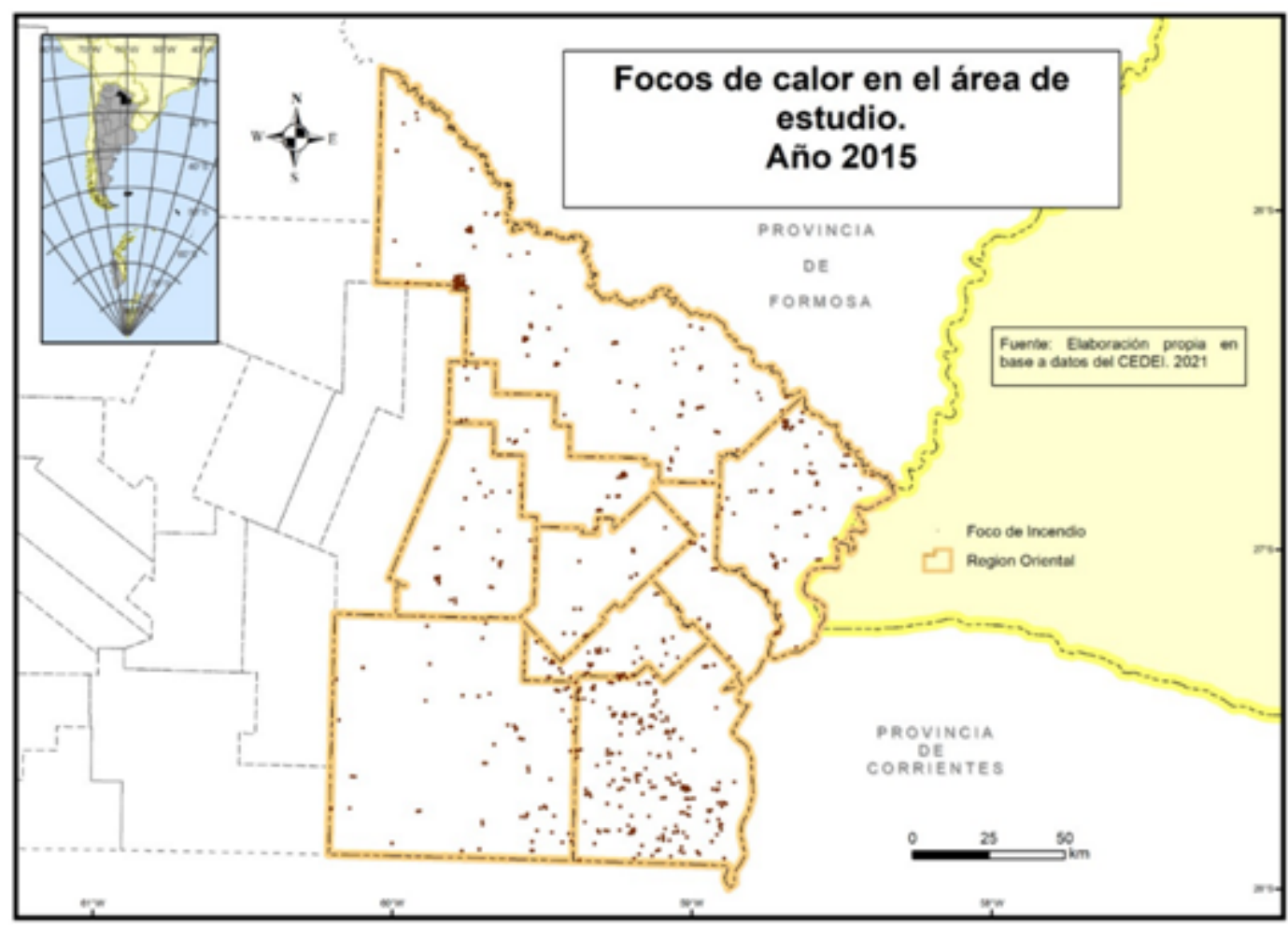

Fuente: Elaboración propia sobre la base de datos del Cedei, 2021

Por otra parte, el mapa N. 3 nos muestra la cantidad de focos de calor que se registraron durante el año 2020 en el área de estudio. Como ya se apreció en el gráfico N. 3 , en el 2020 hubo 4.500 focos de incendio con una confianza igual o superior al $70 \%$; esto significó que aproximadamente unas 63.000 hectáreas fueron afectadas, con importantes daños en bosques nativos e implantados. También afectaron a la fauna silvestre, deterioraron los suelos y perjudicaron la cobertura de rastrojos y a la hacienda. Si a esto le sumamos las pérdidas ocasionadas por los déficits hídricos a causa de la sequía, generaron una situación tan problemática que llevó a que se decretara una emergencia agropecuaria por el término de 180 días.

Uno de los focos de combustión de la región estudiada son los pastizales. Con el objeto de limpiar las parcelas de malezas, se aprovechan períodos secos entre junio y agosto y se los quema, práctica común que se realiza para incorporar nuevas tierras agrícolas. Gran parte de los focos detectados obedece a esa situación. Como menciona Landi (2018, p. 78), el pastizal no solo posee características opuestas a las del bosque en cuanto a inflamabilidad y combustibilidad (Jaureguiberry et al., 2011), sino que además es una cobertura que se distingue por presentar fuertes variaciones interanuales de la cantidad de biomasa en respuesta a las condiciones ambientales (Chen et al., 2011). Por otra parte, muchos de los otros focos de calor están relacionados con la quema de microbasurales en zonas urbanas y periurbanas, lo cual denota una clara falta de cultura ambiental. 
MAPA N. ${ }^{\circ} 3$

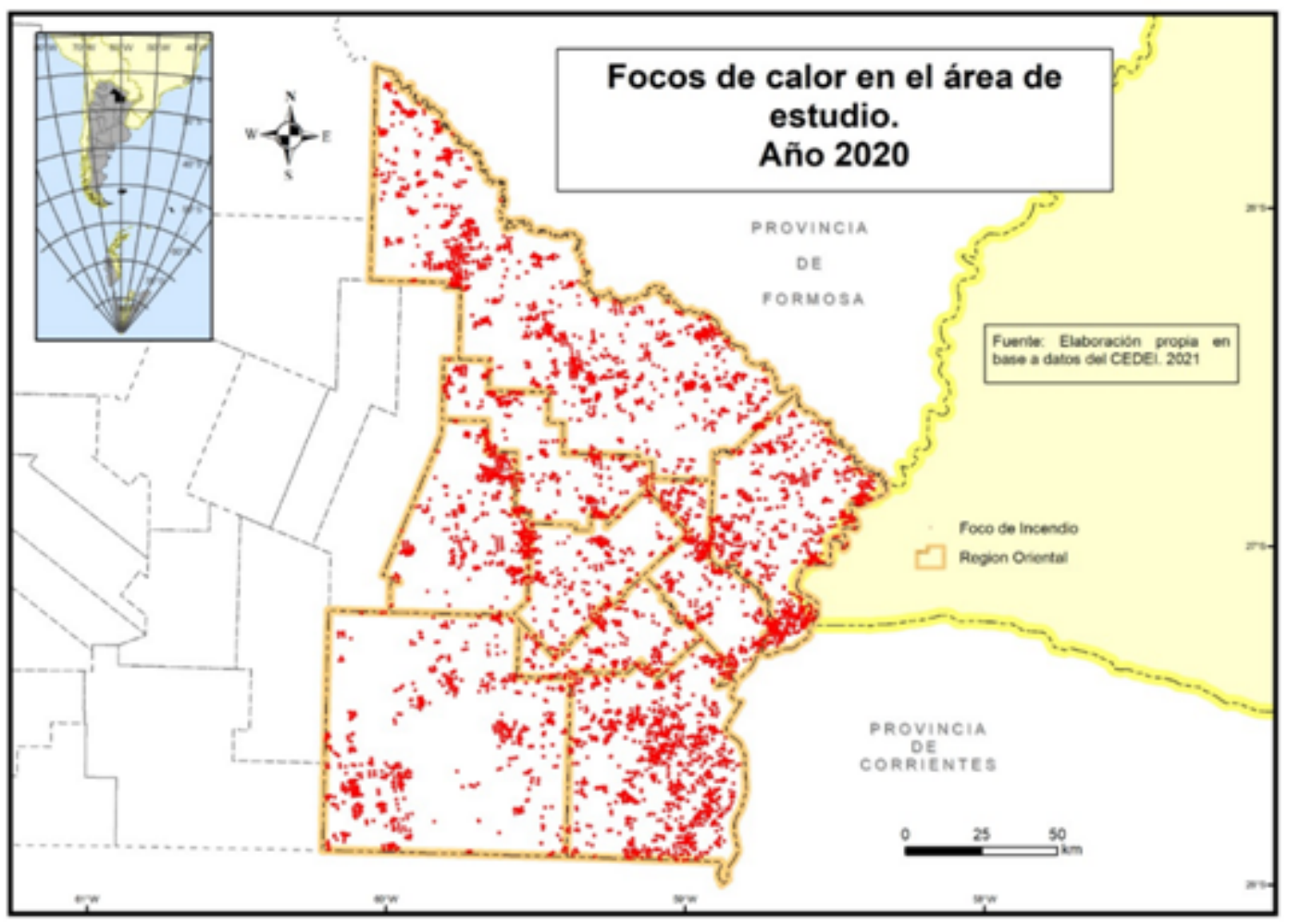

Fuente: Elaboración propia con base en datos del Cedei, 2021

El gráfico N. 4 muestra la cantidad total de focos de calor que pudieron ser identificados en los diferentes departamentos que integran el área de estudio entre los años 2015 y 2020. Allí se aprecia que Libertador General San Martín es el que más focos ígneos tuvo en ese período (2.374 en total), seguido de San Fernando (1.918) y Bermejo (1.159); en tanto que Sargento Cabral registró el menor número, 403 en total.

GRÁFICO N. ${ }^{\circ} 4$

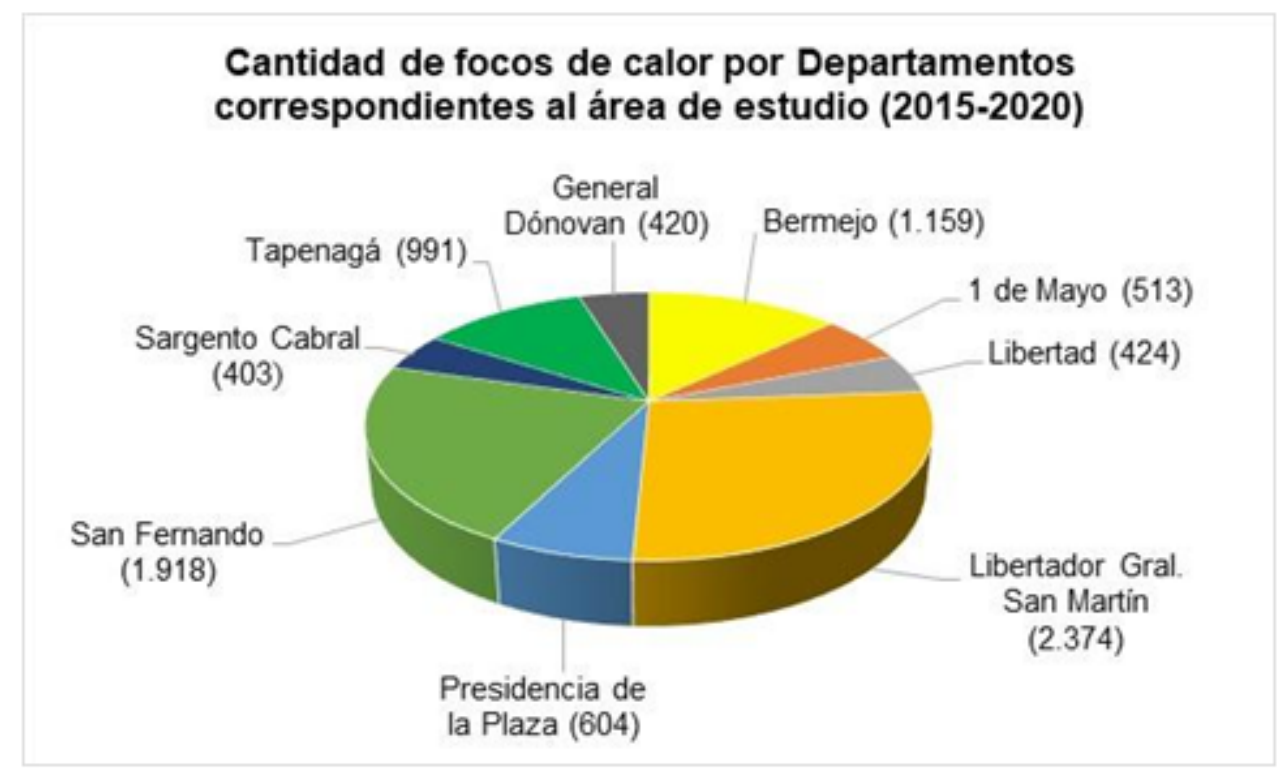

Fuente: Elaboración propia con base en estadística del Cedei. 2021 


\section{RELACIÓN ENTRE SEQUÍA E INCENDIOS EN EL CHACO}

La sequía es uno de los factores climáticos que más incidencia tiene en la aparición de incendios forestales o rurales, ya que es durante estos períodos prolongados sin lluvia cuando se acumula una mayor cantidad de combustible seco orgánico, lo cual aumenta considerablemente el riesgo de que se inicie el fuego. Por esta razón fueron representadas las diferentes zonas de sequía en la provincia del Chaco para el año 2020. Para ello se procedió a georreferenciar la información tomada del Sistema de Información para Sequías para el Sur de Sudamérica - SISSA, donde las categorías de sequía se asignan según las especificaciones del United States Drought Monitor.

En el mapa N. 4 fueron representadas las zonas de sequía en el territorio provincial para el año 2020. Allí se muestran las diferentes categorías de sequía sombreadas con distintos colores. Las zonas amarillas indican condiciones "anormalmente secas" a las que no se considera propiamente sequía, sino que refieren a áreas que pueden estar entrando o recuperándose de condiciones secas. Las categorías restantes refieren a cuatro grados de sequía de severidad creciente: los tonos anaranjados claro indican "sequía moderada"; el anaranjado, "sequía severa"; el rojo, "sequía extrema" y el bordó, "sequía excepcional". Las áreas blancas, categorizadas como "no seco", indican que están experimentando condiciones normales a húmedas.

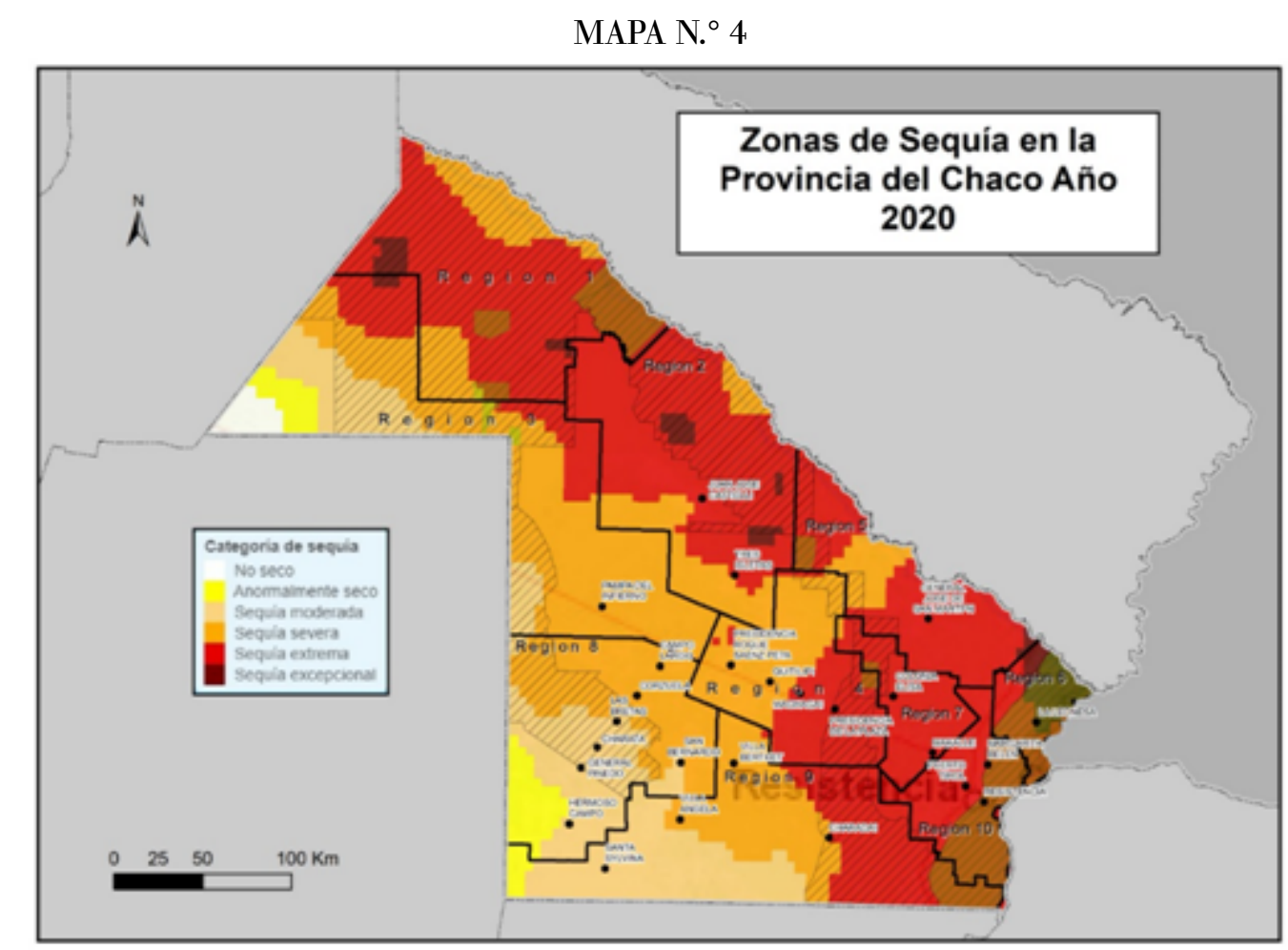

Fuente: Elaboración propia sobre la base del Sistema de Información sobre Sequías para el Sur de Sudamérica (SISSA).

En la Argentina, según información brindada por el Servicio Meteorológico Nacional, el 2020 se ha reportado como el año más seco desde 1961, y el mes de octubre resultó el más seco históricamente desde ese año. Esta situación anómala también se dio en la provincia del Chaco, como puede observarse en el mapa N. 4. Con el objetivo de poder apreciar con más detalle nuestra área de estudio se elaboró el mapa $\mathrm{N} .^{\circ} 5$, donde se observa que gran parte de este espacio geográfico ha presentado durante el año 2020 situaciones compatibles con las categorías “sequía extrema” y "sequía excepcional”. De este modo se evidencia una correlación directa entre el déficit de humedad en el suelo y la ocurrencia de los focos ígneos durante ese año, algunos de los cuales han sido de grandes proporciones. 
MAPA N. ${ }^{\circ} 5$

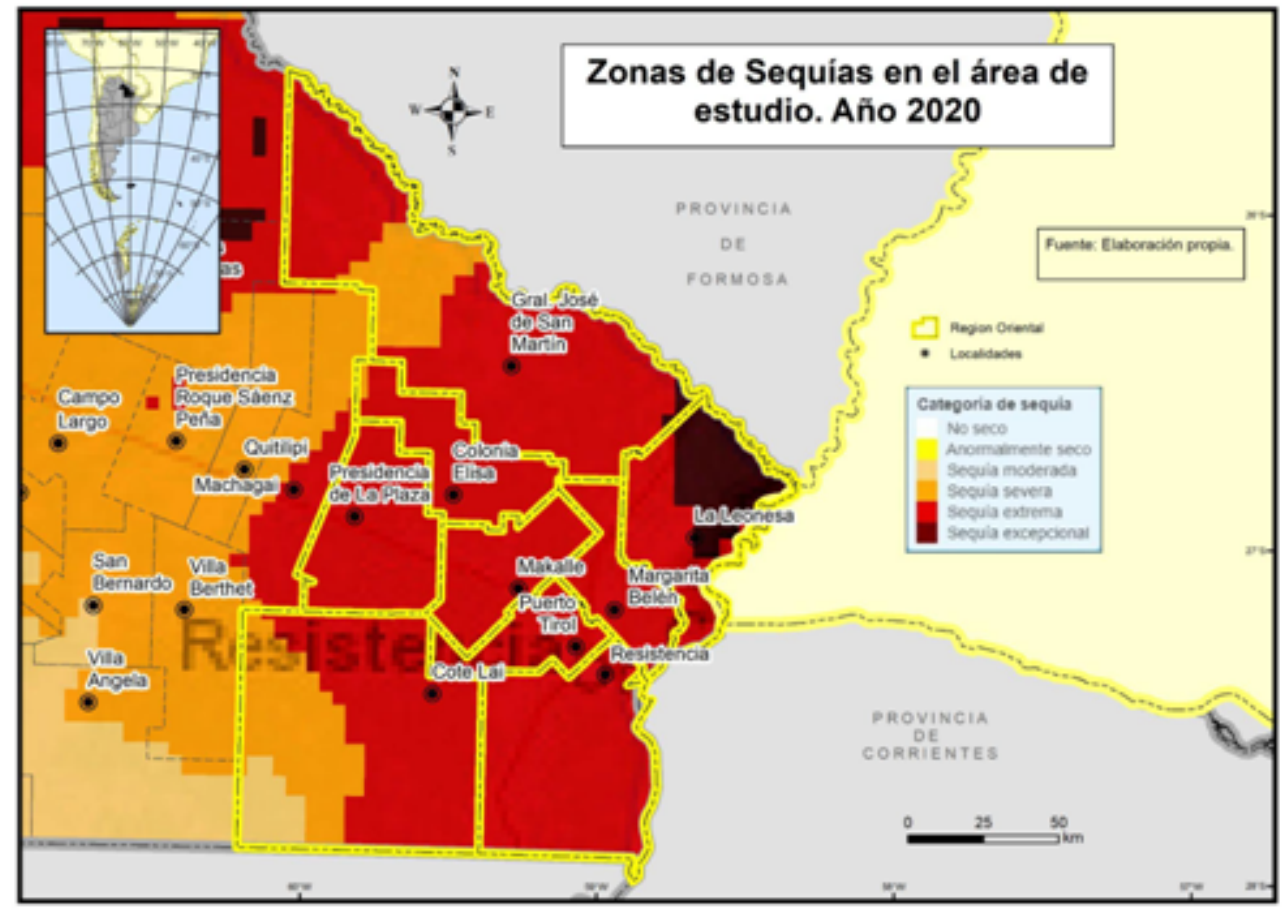

Fuente: Elaboración propia sobre la base del Sistema de Información sobre Sequías para el Sur de Sudamérica (SISSA).

Estas características de la sequía son acentuadas por la situación climática regional. El evento de "La Niña" favoreció el déficit de precipitaciones al menos hasta fin de año. Se trata de un fenómeno estructural, pues estamos en un proceso de calentamiento global que ha hecho que el período que va de enero a septiembre de 2020 haya sido el segundo más cálido en los registros globales, y septiembre de 2020, el más cálido (Magnani, 2020). Este escenario de cambio climático caracterizado por la variabilidad de precipitaciones y la cada vez mayor ocurrencia de fenómenos extremos (las inundaciones del 2019 y las sequías del 2020, por ejemplo) explican en gran medida las condiciones favorables para el desarrollo de incendios en la región.

\section{IMPACTOS AMBIENTALES DE LOS INCENDIOS FORESTALES Y RURALES}

Como se señaló, una de las grandes responsables del fuego es la deforestación, práctica llevada adelante por productores agropecuarios y por quienes desarrollan proyectos de especulación inmobiliaria, que produce consecuencias acumulativas del desastre ambiental a corto plazo. Se genera un círculo vicioso que afecta al medio ambiente, ya que las sequías son el resultado de la deforestación de años anteriores, y a su vez, causas relevantes de los incendios, los cuales en un futuro provocarán nuevas sequías que a su turno realimentan el ciclo de catástrofes naturales.

En términos generales, los principales impactos del fuego se dan sobre el medio biológico, sobre el suelo, los animales y las personas.

Con respecto a los impactos ambientales sobre el medio biológico, el fuego genera una alteración significativa en el sistema natural que provoca la pérdida de biomasa, estructura vegetal, fragmentación de hábitats y pérdida de especies endémicas de la región. Se ven afectados los servicios ecosistémicos que brindan los distintos ambientes, como los valiosos aportes de humedales y bosques. El impacto más notorio sobre la fauna lo representa la pérdida de su hábitat y nichos ecológicos, pues luego del fuego se reducen la diversidad y su abundancia relativa, con un efecto prolongado en el tiempo. Por otro lado, mientras la destrucción de los hábitats de los animales afecta fuertemente a las especies con menor movilidad, otras escapan del incendio y 
se refugian en sitios diferentes, donde generan una presión sobre el nuevo ambiente y provocan desequilibrios en el ecosistema. Asimismo, la competencia entre especies es mayor, escasean fuentes de agua y recursos para la alimentación, y consecuentemente se ven afectadas las redes tróficas del sistema (Servicio Nacional de Manejo de Fuego, 2020).

También las propiedades fisicoquímicas del suelo sufren alteraciones a causa de los incendios: cuanto más elevada es la temperatura del fuego, mayores daños causa en la materia orgánica. Por lo tanto, cuanto más severo el fuego, más amplia la pérdida de nutrientes. La velocidad de liberación de estos últimos por la quema es mucho mayor a la del proceso biológico, y esos nutrientes no pueden ser captados por la comunidad vegetal a la velocidad de liberación. Los procesos claves durante e inmediatamente después del fenómeno son la convección de cenizas, la volatilización, mineralización, erosión, escurrimiento y lixiviación (Servicio Nacional de Manejo de Fuego, 2020).

El suelo constituye la base del ecosistema forestal; por ende, al exponerse a eventos extremos como un incendio podrá sufrir la desaparición temporal de la cubierta vegetal, situación que lo convierte en un sistema muy frágil y vulnerable a la degradación.

En cuanto a nuestra área de estudio en particular, puede decirse que en el año 2020 se dieron condiciones críticas, como la gran cantidad de meses con déficit hídrico y las jornadas marcadas por temperaturas superiores a $40{ }^{\circ} \mathrm{C}$ con prevalencia de viento norte fuerte, que han provocado (en forma conjunta con intervenciones humanas) un total de 4.500 focos ígneos. Las principales consecuencias directas fueron el daño causado en miles de hectáreas de bosques nativos e implantados y cientos de animales afectados, como por ejemplo en el departamento Tapenagá, donde muchos campos con pasturas naturales - que producen los mejores novillos de la provincia - fueron alcanzados por las llamas y al romperse parte de los alambrados, los propietarios tuvieron que liberar al ganado.

Algunos de esos focos de incendio fueron iniciados mediante una quema inadecuada de pastizales en los campos y de basura en zonas periurbanas, que en ocasiones originaron un fuego descontrolado cuyo humo perjudica la salud de las personas, altera la visibilidad en caminos y rutas, y puede provocar accidentes de tránsito. En sectores próximos a rutas provinciales el fuego alcanzó a quemar algunos postes y generó daños en el sistema de tendido eléctrico, una situación de gran riesgo para las viviendas que se encuentran cerca.

\section{El manejo de FUego en la Provincia del Chaco}

Según la Secretaría de Desarrollo Territorial y Ambiente de la provincia del Chaco, en materia de incendios nuestro territorio está supervisado por el Sistema Provincial de Manejo de Fuego, que se encarga de monitorear, prevenir, controlar e informar sobre peligros de focos de incendios en zonas rurales y periurbanas. El mismo está integrado por varios organismos: una red de bomberos que tienen la función de combatir los diferentes incendios que se detectan — divididos en dos brigadas de Administración de Parques Nacionales, siete cuarteles de Bomberos de la Policía del Chaco y 24 cuarteles de Bomberos Voluntarios, reconocidos, operativos y asegurados-; también aportan información y apoyo la Administración Provincial del Agua (APA) y la Empresa del Estado que se encarga del servicio de Agua y su mantenimiento (SAMEEP); Defensa Civil; Dirección de Aeronáutica; Secretaría de Desarrollo Territorial y Ambiente (a través de una Brigada Operativa Ambiental); Secretaría de Municipios y cada municipio en particular; Dirección Provincial de Vialidad y Consorcios Camineros y el Instituto de Agricultura Familiar y Economía Popular para el fortalecimiento de la producción rural.

En cuanto al área comprendida por los nueve departamentos que conforman el este de la provincia del Chaco, la red de bomberos que combaten los incendios forestales está conformada por una brigada de la Administración de Parques Nacionales (ubicada en el Parque Nacional Chaco) en Capitán Solari, tres cuarteles de Bomberos de la Policía del Chaco (en las localidades de General San Martín, Resistencia y Presidencia de la Plaza), y diez cuarteles de Bomberos Voluntarios (en las localidades de Resistencia, 
Barranqueras, Fontana, Puerto Vilelas, Isla del Cerrito, Margarita Belén, Las Palmas, Makallé, La Escondida y Colonia Elisa).

Si consideramos la totalidad de datos detectados por el Satélite VIIRS -NPP Soumi- FIRMS-NASA, y Focos Diarios del Sistema Nacional para la Gestión Integral del Riesgo (SINAGIR), en el 2020 se registró en toda la provincia del Chaco una cifra récord de poco más de 48000 focos de incendios, de los cuales 4.500 - considerando los datos con más del $70 \%$ de confianza- corresponden a nuestra área objeto de estudio. En ese marco crítico se ejecutó el Plan Provincial contra la Sequía y los Incendios Rurales, al cual el gobierno provincial destinó una inversión de 100 millones de pesos para los municipios afectados por sequías e incendios, con los siguientes objetivos: fortalecer la red de colaboración para atención de incendios; generar un sistema de alerta temprana para la prevención y mitigación; unificar el sistema de información de causas y daños; financiar a los municipios la adquisición de tanques de agua, cisternas, obras menores y logística para la distribución de agua; fortalecer divisiones de bomberos de la policía; y garantizar combustible para la logística de bomberos voluntarios y mínimo equipamiento (Sistema Provincial de Manejo de Fuego, 2020).

\section{CONSIDERACIONES FINALES}

La prolongada sequía sufrida en la provincia del Chaco durante el año 2020, sumada a la intervención humana sobre todo en los cambios de uso del suelo producto del desmonte y el avance en busca de pasturas, han provocado el escenario favorable para que se produzca una gran cantidad de incendios forestales y rurales como no se veían desde hace tiempo. Esta situación también fue padecida por provincias como Córdoba, Entre Ríos, Salta, San Luis, entre otras, que sufrieron daños ambientales importantes, con grandes pérdidas en la actividad agropecuaria y destrucción de miles de hectáreas de bosques nativos.

En la región comprendida por los nueve departamentos del sector oriental del Chaco (Libertador General San Martín, Sargento Cabral, Presidencia de la Plaza, General Dónovan, Libertad, Tapenagá, San Fernando, $1^{\circ}$ de Mayo y Bermejo), se registraron durante el año 2020 un total de 4.500 focos de incendios (correspondientes a aquellos registros con más del $70 \%$ de confiabilidad). Estos afectaron de un modo u otro a un total de 63.000 hectáreas aproximadamente, extensión que representó casi la misma superficie impactada por incendios en las otras tres provincias del NE según datos del Servicio Nacional de Manejo de Fuego: en Corrientes fueron 45.340 hectáreas; en Formosa, 20.459 ha y en Misiones, 2.194 ha.

Si bien los incendios van a ser cada vez más frecuentes, también es cierto que hoy existen más herramientas con información valiosa para la gestión de las emergencias. Nuestra provincia posee el Sistema Provincial de Manejo de Fuego, organismo que se encarga de monitorear, prevenir, controlar e informar sobre la existencia de focos de incendios para actuar en consecuencia, esto es, evitar que ocurran y detener su propagación.

En ocasiones esto pareciera no ser suficiente porque existe una clara falta de responsabilidad social: las leyes actuales que sancionan las quemas intencionales de bosques, productos forestales y vegetaciones parecen ser insuficientes para desmotivar a los autores de las mismas.

Lo cierto es que cuando el fuego se controla no termina todo el problema, sino que empieza otro: el referido al impacto que las llamas dejan en el ambiente, además de los daños económicos que provocan. En el corto plazo es difícil medir o cuantificar el verdadero daño ambiental; el paso del fuego degrada los suelos y les quita fertilidad. A la vez, atenta contra la biodiversidad, arrasa con las pasturas que sirven de alimento a los animales y con distintas especies arbóreas que forman parte del bosque; así pues, al disminuir la vegetación hay menos generación de oxígeno, lo cual indefectiblemente altera el comportamiento climático.

Por último, solo queda destacar que la educación ambiental y las buenas prácticas agrícolas nos muestran la importancia de tener preparada una estrategia clara para enfrentar los focos. 


\section{ReFERENCIAS}

Alberto, J. (2006). El Chaco Oriental y sus fisonomías vegetales. Revista Geográfica Digital, 3 (5). Recuperado de htt ps://revistas.unne.edu.ar/index.php/geo/article/view/2823/2503

Argentina Forestal (2020). Incendios en la Argentina: es necesaria una ley integral de Ordenamiento Ambiental del territorio. https://www.argentinaforestal.com/2020/09/11/incendios-en-la-argentina-es-necesaria-una-leyintegral-de-ordenamiento-ambiental-del-territorio/

Centro de Documentación e Información del Chaco - Cedei (2021). Recuperado de http://cedei.produccion.chaco .gov.ar/?page_id $=10073$

Chen, F., Weber, K., Anderson, J. y Gokhal, B. (2011). Assessing the susceptibility of semiarid rangelands to wildfires using Terra MODIS and Landsat Thematic Mapper data. International Journal of Wildland Fire 20(5), 690-701. https://doi.org/10.1071/WF10001

Comisión Nacional de Actividades Espaciales - Conae (2014). Instructivo para visualizar información sobre focos de calor proveniente del instrumento MODIS. Recuperado de https://catalogos.conae.gov.ar/focos/Instructivo-Vis ualizacion-Focos-De-Calor.pdf

Cuadra, D. (2012). La problemática forestal en la provincia del Chaco, Argentina. Un análisis desde la Geografía. Revista Geográfica Digital, 9(18). Recuperado de https://revistas.unne.edu.ar/index.php/geo/article/view/2232

Dennis, E.; Nasi, R.; Meijaard, Applegate, G. y Moore, P. (2001). Los incendios forestales y la diversidad biológica. Recuperado de http://www.fao.org/3/y3582s/y3582s08.htm

Di Bella, C. M.; Posse, G.; Beget, M. E.; Fischer, M. A.; Mari, N. y Veron, S. (2008) La teledetección como herramienta para la prevención, seguimiento y evaluación de incendios e inundaciones. Revista científica y técnica de ecología y medio ambiente, 17 (3), 39-52. Recuperado de https://www.revistaecosistemas.net/index.php/ecosistemas/a rticle/view/85

Ginzburg, R. y Adámoli, J. (2005). Situación ambiental en el Chaco Húmedo. La situación ambiental Argentina 2005. Ecorregión Chaco Húmedo. Recuperado de http://www.oab.org.ar/capitulos/cap05.pdf

Instituto Geográfico Nacional. Capas SIG. https://www.ign.gob.ar/NuestrasActividades/InformacionGeoespacial/ CapasSIG

Instituto Nacional de Pesquisas Espaciais -INPE- (2021). Monitoramento de Queimadas em Tempo Quase-Real do INPE. Brasil. http://www.inpe.br/queimadas/ (consultada 26/05/21)

Jaureguiberry, P.; Bertone, G. y Díaz, S. (2011). Device for the standard measurement of shoot flammability in the field: flammability measurement in the field. Austral Ecology 36 (7), 821-829.

Kunst, C. (2011). Ecología y uso del fuego en la región chaqueña argentina: Una revisión. Boletín del CIDEU, 10, $81-$ 105 Recuperado de https://dialnet.unirioja.es/servlet/articulo?codigo $=3870714$

Kunst, C.; Bravo, S. y Panigatti, J. (2003). Fuego en los ecosistemas argentinos. Santiago del Estero: Ediciones INTA.

Landi, M. L. (2018). Caracterización del régimen de incendios, su relación con el clima y su efecto en la resiliencia y estructura de la vegetación. Instituto de Diversidad y Ecología Animal. Universidad Nacional de Córdoba. Recuperado de: https://ri.conicet.gov.ar/bitstream/handle/11336/117532/CONICET_Digital_Nro.03acc3b 4-211d-4210-9f5f-f9a35d3dc3b7_A.pdf?sequence=2\&isAllowed=y

Ley N. 26.815. Presupuestos Minimos de Protección Ambiental en Materia de Incendios Forestales y Rurales. Disponible en https://argentinambiental.com/legislacion/nacional/ley-26815-incendios-forestales-rurales/

Magnani, R. (1 de noviembre de 2020). Incendios en la Argentina: 2020 ya es el año con más focos del Siglo XXI. Diario Clarin. https://www.clarin.com/sociedad/incendios-argentina-2020-ano-focos-siglo-xxi_0_5UT3P4Q am.html

Ministerio de Ambiente y Desarrollo Sostenible. Servicio Nacional de Manejo de Fuego. ¿Qué es un incendio forestal?. Recuperado de: https://www.argentina.gob.ar/ambiente/fuego/conocemas/incendioforestal

Morello, J. y Adámoli, J. (1968). Las grandes unidades de vegetación y ambiente del Chaco Argentino. Primera parte: Objetivos y metodología. Instituto Nacional de Tecnología Agropecuaria. Serie Fitogeográfica, 10,1-125. 
Navarro, L. M. (2016). Caracterización espacio temporal de los incendios en la provincia de Chaco y su relación con las actividades antrópicas. Facultad de Agronomía. Universidad de Buenos Aires. Recuperado de http://ri.agro.uba .ar/files/download/tesis/especializacion/2020navarroluismiguel.pdf

Nemirovsky, Y. (11 de septiembre de 2019). ¿Por qué se están quemando los bosques sudamericanos y qué hacer para cuidarlos?. https://www.argentinaforestal.com/2019/09/11/por-que-se-estan-quemando-los-bosques-sudamer icanos-y-que-hacer-para-cuidarlos/

Puig Soler, C. (5 de junio de 2020). El porqué de los incendios en Australia. La Vanguardia. https://www.lavanguard ia.com/natural/20200605/481596919860/el-por-que-de-los-incendios-en-australia.html

Servicio Nacional de Manejo de Fuego (31 de diciembre de 2020). Reporte de Incendios. Ministerio de Ambiente y Desarrollo Sostenible Argentina. https://www.argentina.gob.ar/sites/default/files/31-dic-reporte_incendios_.p df

Servicio Nacional de Manejo de Fuego (2021). Ministerio de Ambiente y Desarrollo Sostenible de la Nación Argentina. https://www.argentina.gob.ar/ambiente/manejo-del-fuego

SIB (Sistema de Información de Biodiversidad) (2016). Nueva herramienta para la detección de focos de calor. Publicado el 9/3/16. Disponible en: https://sib.gob.ar/novedades/nueva-herramienta-para-la-deteccion-de-focos-de-calor

SISSA (Sistema de Información para Sequías para el Sur de Sudamérica). Estado actual de la sequia. https://sissa.crcsas.org/monitoreo/estado-actual-de-la-sequia/

Sistema Provincial de Manejo de Fuego (2020). Secretaría de Desarrollo Territorial y Ambiente. Provincia del Chaco.

Vegas, J. (19 de enero de 2020). ¿Qué hay detrás de los incendios de Australia y cómo se han producido?. Clima Argentina. https://www.clima.com/noticias/cual-es-la-causa-de-los-incendios-de-australia 